\title{
Relationship between dual-task related gait changes and intrinsic risk factors for falls among transitional frail older adults
}

\author{
Olivier Beauchet ${ }^{1,2}$, Véronique Dubost ${ }^{1}$, François Herrmann ${ }^{1,2}$, Muriel Rabilloud ${ }^{3}$, Régis Gonthier ${ }^{1}$, \\ and Reto W. Kressig ${ }^{2}$ \\ ${ }^{1}$ Department of Rehabilitation and Geriatrics, Geneva University Hospitals, Geneva, Switzerland, \\ ${ }^{2}$ Department of Geriatrics, Saint-Etienne University Hospitals, Saint-Etienne, ${ }^{3}$ Department of Biostatistics, \\ Lyon University Hospitals, Lyon, France
}

ABSTRACT. Background and aims: Gait changes in dual-task conditions have been associated with an increased risk of falling in older adults, and become more important in increasingly frail older adults. We studied the relationship between commonly known intrinsic risk factors for falls and dual-task related gait changes among transitional frail older adults. Methods: Walking time and number of steps were measured while walking alone and while walking with counting backward on a 10-m walkway in 66 transi-

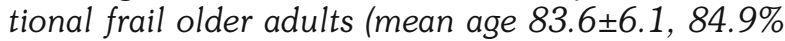
women). Uni- and multiple linear regression analyses were performed to explore the relationship between dual-task related gait changes (walking time and number of steps) and age over 85 years, polymedication, psychoactive drugs, poor distance vision, abnormal mobility and cognitive impairment. Results: Compared with walking alone, both walking time and number of steps increased significantly while counting backward $(\mathrm{p}<0.001)$. Polymedication and abnormal mobility were associated with a significant increase of walking time and number of steps $(\mathrm{p}<0.01$ for unadjusted change, $\mathrm{p}<0.05$ for adjusted change). Conclusions: Dual-task related gait changes were closely correlated with polymedication and impaired mobility in our sample of transitional frail older adults. These findings give some insight into the complexity of performing attention-demanding tasks while walking and accentuate the need for multi-factorial, personalized intervention strategies, to prevent decline in dual-task performance in this fall-prone population.

(Aging Clin Exp Res 2005; 17: 270-275)

${ }^{\circ} 2005$, Editrice Kurtis

\section{INTRODUCTION}

Detection of increased risk of falling is essential for efficient fall prevention among older adults (1). Several intrinsic (subject-related) risk factors for falls among older adults have been identified, such as age over 85 years, polymedication, psychoactive drugs, poor vision, abnormal mobility, and cognitive decline (2-7). Unfortunately, fall risk assessment models based on these multiple factors are usually of little use in general practice, because they are not easy to apply (8). Therefore, the development of a simple fall risk screening tool remains an important challenge for fall prevention in the elderly.

Changes in gait characteristics due to a simultaneously performed attention-demanding task have frequently been reported in the elderly $(9,10)$. We recently showed that a walking-associated arithmetic task provoked major gait changes in transitional frail older adults (11). There is also some evidence about a relationship between dual-task related gait changes and the risk of falling (12-14). In 1997, Lundin-Olsson et al. (13) were the first to establish a link between the inability to walk and talk at the same time, and the occurrence of falls. This simple screening test dependably predicted falls in the studied sample of older adults. However, these data have never been confirmed since and, in spite of the development of other similar dual-task-based fall risk assessment tests (12), findings about the relationship between dual-task related gait changes and falls remain controversial (12). Therefore, to find out more about the association of dual-task related gait performance with established fall risk factors in the literature may improve our understanding of dual-task performance and its possible relationship with falls.

Key words: Dual-task, elderly, fall risk, frailty, gait.

Correspondence: O. Beauchet, MD, PhD, Department of Rehabilitation and Geriatrics, Geneva University Hospitals, CH-1226 ThonexGeneva, Switzerland.

E-mail: olivier.beauchet@hcuge.ch

Received May 14, 2004; accepted in revised form November 10, 2004. 
Previous reports have shown that dual-task related gait changes depend on individuals' state of health. Compared with healthy control subjects, dual-task related gait changes were significantly more frequent among older adults with Alzheimer's (15) or Parkinson's disease (16). Moreover, dual-task related gait changes become more frequent in increasingly frail older adults who also show an increasing risk of falling $(11,13,14)$. To study how frail older adults cope with gait-associated dual tasks may provide more insight into gait disorders and possibly related fall mechanisms among this fall-prone population.

Older adults' state of health may vary considerably because of the various cumulate effects of chronic diseases and physiologic decline (17). These effects become even more pronounced and diverse with age, contributing to a vicious cycle of increasing frailty and increasing risk of falling. In order to make geriatric study findings more specific and meaningful, definition of participants' state of health or degree of frailty seems important. Only a few studies have addressed gait in frail older adults $(13,14)$ but without using specific criteria for the degree of frailty. Speechley and Tinetti (18) developed a classification of frailty which distinguishes vigorous, transitional, and frail older adults, and found that an increased risk of falling is directly related to a higher degree of frailty. Transitional frail older adults are at high risk of functional loss after a fall, and are therefore considered as an important target group for early detection of risk of falling.

We hypothesized that intrinsic risk factors for falls would influence gait among transitional frail older adults performing a walking-associated arithmetic task. The aims of this study were: 1 ) to quantify dual-task related gait changes among transitional frail older adults while performing a mental arithmetic task; and 2) to establish whether intrinsic risk factors for falls are associated with dual-task related gait changes.

\section{METHODS}

\section{Participants}

Of 380 eligible older adults, 132 (34\%) agreed to participate. Sixty-six (50\%) participants met the inclusion criteria of transitional frailty based upon Speechley and Tinetti's classification (18) of older adults into vigorous, transitional, and frail categories, and were included after having given their informed consent. A physical examination was performed to rule out the following exclusion criteria: history of falls in the past year; acute medical illness in the past 3 months (e.g. coronary heart disease, heart failure, pulmonary infection); neurological diseases such as Parkinson's disease, cerebellar disease, myelopathy, peripheral neuropathy and severe cognitive impairment (score for Mini Mental State Examination of Folstein $<16 / 30$, (19)); depressive symptoms (score for 15-item Geriatric Depression Scale >4, (20); major orthopedic di- agnoses involving the lower back, pelvis or lower extremities; use of walking aids. In case of moderate cognitive impairment $(16<$ score MMSE<25), information on fall history and diseases were obtained by a person who lived with the subject.

Baseline assessment included: sensory or motor deficit involving lower extremities, number of chronic diseases such as cardiovascular disease, diabetes mellitus or chronic obstructive pulmonary disease. We also took note of prescribed psychoactive drugs, including benzodiazepines, antidepressants and neuroleptics, and of the number of drugs taken per day by record review. Other data were collected using standard instruments of geriatric assessment. Distance vision was measured at $5 \mathrm{~m}$ and near vision at $0.5 \mathrm{~m}$ with a Snellen letter test chart (21). Vision was assessed with corrective lenses if used by the subject. Poor vision was defined as a visual acuity $<6$. Basic mobility was assessed with the Timed Up \& Go test (22). Abnormal mobility was defined as time $\geq 20$ seconds. Cognitive impairment was defined on MMSE score $<25$. None of the participants was familiar with the specific purpose of the study. They were told that they were taking part in the development of a fall risk screening tool based on evaluation of gait in dual-task conditions. The study was conducted in accordance with the ethical standards set forth in the Helsinki Declaration (1983). The local ethics committee approved the project.

\section{Tasks}

Participants were asked to perform, in randomized order, the following tasks: walking alone at usual speed over a distance of 10 meters; counting backward out loud from 50 while sitting on a chair; and both tasks simultaneously (walking while counting backward). For the dual-task condition, subjects were told to maintain their usual walking speed. Before testing, a trained evaluator gave standardized verbal instructions regarding the test procedure with a visual demonstration of the walking test.

Each subject completed one trial for all three testing conditions. The walking trials were performed on a 10-meter walkway in a well-lit environment. Subjects walked at their self-selected speed and wore their own footwear. To ensure safety, a belt was placed around each subject's waist for easy grasp by a research assistant who walked behind the subjects during all the trials. Each walking trial was recorded by a Sony DCRPC6E video numeric camera placed on a tripod in front of the walkway. Walking time in seconds and number of steps were noted. Both the acceleration and deceleration phases of gait were included for analysis. The cognitive task performance (number of enumerated figures in single- and dual-task conditions) was also recorded with a tape recorder, to document subjects' capacity to perform the dual task. 
Table 1 - Baseline characteristics of transitional frail older adults $(n=66)$.

\begin{tabular}{|c|c|}
\hline Characteristics & Value \\
\hline $\begin{array}{l}\text { Age } \\
\text { Mean } \pm \text { SD (years) } \\
>85 \text { years, } \mathrm{n}(\%)\end{array}$ & $\begin{array}{l}83.6 \pm 6.2 \\
26(39.4)\end{array}$ \\
\hline Female gender, $\mathrm{n}(\%)$ & $56(84.9)$ \\
\hline $\begin{array}{l}\text { Number of drugs taken per day } \\
\text { Mean } \pm \text { SD } \\
>3 \text { per subjects, } n(\%)\end{array}$ & $\begin{array}{c}5 \pm 3 \\
47(72.3)\end{array}$ \\
\hline Psychoactive drugs*, n (\%) & 29 (43.9) \\
\hline $\begin{array}{l}\text { Distance vision score }(/ 10) \\
\quad \text { Mean } \pm \mathrm{SD} \\
<6, \mathrm{n}(\%)\end{array}$ & $\begin{array}{c}6 \pm 2.5 \\
37(56.9)\end{array}$ \\
\hline $\begin{array}{l}\text { Timed "Up \& Go" (in seconds) } \\
\text { Mean } \pm \text { SD } \\
\geq 20, \mathrm{n}(\%)\end{array}$ & $\begin{array}{l}23.2 \pm 6.6 \\
42(63.6)\end{array}$ \\
\hline $\begin{array}{l}\mathrm{MMSE}^{\dagger} \text { score }(/ 30) \\
\text { Mean } \pm \text { SD } \\
<25, \mathrm{n}(\%)\end{array}$ & $\begin{array}{l}25.1 \pm 3.6 \\
25(37.9)\end{array}$ \\
\hline Frail attributes by Speechley and Tinetti criteri & \\
\hline Age $\geq 80$ years, $n(\%)$ & $49(74.2)$ \\
\hline Impaired gait/balance $e^{\ddagger}, \mathrm{n}(\%)$ & $41(62.1)$ \\
\hline No walking for exercise, $\mathrm{n}(\%)$ & $48(72.7)$ \\
\hline No other physical exercise ${ }^{\S}, \mathrm{n}(\%)$ & $46(69.7)$ \\
\hline Depression $^{\infty}, \mathrm{n}(\%)$ & $13(19.7)$ \\
\hline Intake of psychoactive drugs ${ }^{*}, \mathrm{n}(\%)$ & $30(45.5)$ \\
\hline Impaired near vision ${ }^{\text {II }}, \mathrm{n}(\%)$ & $55(83.3)$ \\
\hline Impaired upper extremity strength" ${ }^{\#}, \mathrm{n}(\%)$ & $4(6.1)$ \\
\hline Impaired lower extremity strength ${ }^{\#}, \mathrm{n}(\%)$ & $3(4.5)$ \\
\hline Lower extremity disability ${ }^{\#}, \mathrm{n}(\%)$ & $16(24.2)$ \\
\hline
\end{tabular}

$\mathrm{SD}=$ Standard deviation. "Intake of benzodiazepines, antidepressants or neuroleptics; ${ }^{\dagger}$ Mini Mental State Examination of Folstein; ${ }^{\text {TTimed }}$ "Up \& Go" test $\geq 20$ seconds or positive Romberg; 'Exercise: accumulation of $\geq 60$ minutes per week and duration of $6 \geq$ months over past years; ${ }^{\circ}$ Intake of antidepressants; "Binocular vision acuity $<6$ at distance of $50 \mathrm{~cm}$ with Snellen letter test chart; "Reduced limb strength or disability defined as impairment in instrumental daily living activities.

\section{Study variables and outcome measures}

The intrinsic risk factors for falls listed in Table 1 were the study variables. Two outcome measures were used: 1) mean $\pm \mathrm{SD}$ of walking time (in seconds) and of the number of steps for both walking conditions; 2) mean $\pm \mathrm{SD}$ of dual-task related gait changes for walking time (in seconds) and for number of steps calculated from the formula (dual-task - single-task).

\section{Statistical analysis}

Baseline characteristics and gait parameters were summarized descriptively using either means and standard deviations or frequencies and percentages, as appropriate. Comparisons between walking conditions were performed by the paired-sample $t$-test for continuous variables or the chi-square test for nominal variables.

Uni- and multiple linear regression analyses were performed to determine whether intrinsic risk factors for falls were associated with dual-task related changes in walking time and number of steps. The dependent variable was change in walking time in seconds or of number of steps calculated from the formula (dual-task - singletask). Age over 85 years, polymedication ( $>3$ drugs/day), intake of psychoactive drugs, abnormal distance vision (score $<6$ ), abnormal basic mobility (Timed Up \& Go test $\geq 20$ seconds) and cognitive impairment (MMSE $<25$ ) corresponding to intrinsic risk factors for falls were defined as independent variables. The coefficient of regression beta was used to estimate the effect of intrinsic risk factors for falls on dual-task related walking time and number of step changes. $p<0.05$ was considered statistically significant.

\section{RESULTS}

\section{Baseline characteristics}

The baseline characteristics of transitional frail older adults are listed in Table 1. Subjects ranged in age from 71 to 96 years (mean age 83.6) and 39.4\% were aged over 85 . Eighty-four percent were women. They were taking an average of 5 drugs, and $43.9 \%$ took psychoactive drugs. Ninety-three percent of subjects who used psychoactive drugs also took more than 3 drugs per day. The mean score for distance visual acuity was $6 \pm 2.5$, and $56.9 \%$ of subjects had a score $<6$. Abnormal basic mobility was observed in $63.6 \%$, and mean Timed Up \& Go time was $23.2 \pm 6.6$ seconds. The mean MMSE score was 25.1 \pm 3.6 , and cognitive impairment was present in $37.9 \%$. Frail attributes, as determined by the Speechley and Tinetti criteria (18) were as follows: gait or balance impairment $(62.1 \%$ of subjects), no walking for exercise $(72.7 \%)$, no other physical activity (69.7\%). Nineteen percent of the subjects were taking an antidepressant. Intake of psychoactive drugs such as benzodiazepines, antidepressants or neuroleptics was present in $45.5 \%$. Impaired near vision was observed in $83.3 \%$. Impaired upper or lower extremity strength was present in $6.1 \%$ and $4.5 \%$, respectively. Lower extremity disability was found in $24.2 \%$.

Table 2 - Mean value $\pm S D$ of walking time and number of steps while walking alone and while walking with counting backward.

\begin{tabular}{lcc}
\hline & \multicolumn{2}{c}{ Walking } \\
\cline { 2 - 3 } & Alone & $\begin{array}{c}\text { With backward } \\
\text { counting }\end{array}$ \\
\hline Time (seconds) & $15.1 \pm 0.3$ & $21.4 \pm 8.6^{*}$ \\
Steps (number) & $24.8 \pm 7.0$ & $28.9 \pm 9.9^{*}$ \\
\hline
\end{tabular}

$\mathrm{SD}=$ standard deviation. "Compared with walking alone and based on pairedsamples $t$-test with $p$ significant $<0.05$. 
Table 3 - Uni- and multiple linear regression looking for association between changes in walking time while backward counting (dependent variable) and intrinsic risk factors for falls.

\begin{tabular}{|c|c|c|c|c|}
\hline Variables* & $\begin{array}{c}\text { Unadjusted changes }^{\dagger} \\
\left(95 \% \mathrm{CI}^{\dagger}\right)\end{array}$ & $p$-value & $\begin{array}{c}\text { Adjusted changes } \\
(95 \% \text { CI) }\end{array}$ & $p$-value \\
\hline Age $>85$ years & $0.0(-3.1-3.1)$ & 0.983 & $-0.3(-3.2-2.5)$ & 0.812 \\
\hline Number of drugs taken per day $>3$ & $6.1(3.0-9.2)$ & $<0.001$ & $4.6(1.2-8.1)$ & 0.009 \\
\hline Intake of psychoactive drug $§$ & $1.1(-2.0-4.3)$ & 0.466 & $-0.3(-2.6-3.2)$ & 0.831 \\
\hline Abnormal distance vision ${ }^{\infty}($ score $<6)$ & $2.5(-0.6-5.5)$ & 0.115 & $-1.2(-1.8-4.2)$ & 0.439 \\
\hline Abnormal mobility (Timed "Up \& Go" $\geq 20 \mathrm{sec}$ ) & $5.2(2.3-8.2)$ & 0.001 & $3.4(0.1-6.7)$ & 0.049 \\
\hline Cognitive impairment (score MMSEवा <25) & $3.1(0.1-6.2)$ & 0.045 & $1.3(-1.7-4.4)$ & 0.394 \\
\hline
\end{tabular}

* $\mathrm{n}=66$ subjects for whom all data were available, intercept value not shown in table corresponds to value of a transitional frail male older adult aged less than 85 , taking 3 or less drugs/day, not using psychoactive drugs, with normal distance vision, mobility and MMSE score. ${ }^{\dagger} \mathrm{Change}$ in seconds estimated from coefficient of regression beta, corresponding to increase in mean value of walking time while walking with counting backward out loud; ${ }^{\ddagger}$ Confidence interval; §Intake of benzodiazepines, antidepressants or neuroleptics; ${ }^{\infty}$ Vision acuity $<6$ at distance of 5 m with Snellen letter test chart; ${ }^{1}$ Mini Mental State Examination of Folstein.

Clinical observations and performance in single and dual-task conditions

All participants were able to complete the single and dual tasks without falling. As shown in Table 2, walking time and number of steps were significantly higher while counting backward compared with walking alone $(p<0.001)$. Average changes in walking time and number of steps calculated from the formula (dual-task - singletask) were $6.4 \pm 6.2$ seconds and $4.1 \pm 4.2$ steps.

Relationship between intrinsic risk factors for falling and dual-task related gait changes

As indicated in Table 3, polymedication ( $>3$ drugs/day), abnormal basic mobility (Timed Up \& Go test $\geq 20$ seconds) and cognitive impairment (MMSE $<25)$ were significantly associated with an increase in walking time (6.1 seconds, $p<0.001 ; 5.2$ seconds, $p=0.001 ; 3.1$ sec- $^{-}$ onds, $p=0.045$, respectively). After adjusting for all variables in the table, only polymedication ( $>3$ drugs/day) and abnormal basic mobility (Timed Up \& Go test $\geq 20$ sec- onds) explained the increase in walking time (4.6 seconds, $p=0.009 ; 3.4$ seconds, $p=0.049$ ). As shown in Table 4, polymedication ( $>3$ drugs/day) and abnormal basic mobility (Timed Up \& Go test $\geq 20$ seconds) were significantly associated with an increase in number of steps (3.6 steps, $p=0.002$ and 3.9 steps, $p<0.001$ for unadjusted change; 2.4 steps, $p=0.041$ and 2.9 steps, $p=0.012$ for adjusted change).

\section{DISCUSSION}

Our results show that counting backward while walking caused significant gait changes in a sample of transitional frail older adults, and that dual-task related gait changes were significantly related to polymedication ( $>3$ drugs/day) and abnormal mobility (Timed Up \& Go test $\geq 20$ seconds).

Gait changes while performing a cognitive task have previously been reported among older adults (9-14), and mainly depend on the cerebral capacity to switch attentional resources between walking and additional simulta-

Table 4 - Uni- and multiple linear regression looking for association between changes in number of steps while backward counting (dependent variable) and intrinsic risk factors for falls.

\begin{tabular}{|c|c|c|c|c|}
\hline Variables* & $\begin{array}{c}\text { Unadjusted changes }{ }^{\dagger} \\
\left(95 \% \mathrm{CI}^{\dagger}\right)\end{array}$ & $p$-value & $\begin{array}{l}\text { Adjusted change } \\
(95 \% \mathrm{CI})\end{array}$ & $p$-value \\
\hline Age $>85$ years & $-1.2(-3.3-0.9)$ & 0.250 & $-1.6(-3.5-0.4)$ & 0.117 \\
\hline Number of drugs taken per day $>3$ & $3.6(1.4-5.8)$ & 0.002 & $2.4(0.1-4.8)$ & 0.041 \\
\hline Intake of psychoactive drug $§$ & $0.8(-1.3-2.9)$ & 0.461 & $0.2(-1.8-2.2)$ & 0.824 \\
\hline Abnormal distance vision ${ }^{\infty}($ score $<6)$ & $1.5(-0.7-3.6)$ & 0.174 & $0.7(-1.3-2.8)$ & 0.475 \\
\hline Abnormal mobility (Timed "Up \& Go" $\geq 20$ s) & $3.9(2.0-5.9)$ & $<0.001$ & $2.9(0.6-5.2)$ & 0.012 \\
\hline Cognitive impairment (score MMSE ${ }^{\text {पा }}<25$ ) & $1.2(-0.9-3.3)$ & 0.262 & $0.0(-2.1-2.2)$ & 0.971 \\
\hline
\end{tabular}

*n=66 subjects for whom all data were available; intercept value not shown in table corresponds to value of a transitional frail male older adult aged less than 85 , taking 3 or less drugs/day, not using psychoactive drugs, with normal distance vision, mobility and MMSE score. ${ }^{\dagger}$ Changes in number of steps estimated from coefficient of regression beta, corresponding to increase in mean value of number of steps while walking with counting backward out loud; ${ }^{\ddagger}$ Confidence interval; SIntake of benzodiazepines, antidepressants or neuroleptics; ${ }^{\infty}$ Vision acuity $<6$ at distance of $5 \mathrm{~m}$ with Snellen letter test chart; ${ }^{\mathbb{T}}$ Mini Mental State Examination of Folstein. 
neous attention-demanding tasks $(9,23)$. In a review of meta-analyses from studies examining age-related differences in attentional processes among healthy adults, Verhaeghen and Cerella (23) found an age-related deficit for dual-task performance and global task switching. In contrast with this finding, in our study there were no significant age-related gait changes. Our older adults were not healthy and formed part of transitional frail category described by Speechley and Tinetti (18). With the cumulative damage of multiple chronic diseases, walking requires more attentional processing (13-16) in order to compensate the decline in sensorimotor systems and cognitive processes (9), which can diminish any age-related gait change in dual-task condition.

Multiple medication has previously been identified as an important predictor of falls among older adults (3). Cumming et al. (24) reported that the relative risk of falling when taking three or more medications is 2.4. Supporting this data, our study shows that taking more than 3 drugs per day was the best parameter to explain dual-task related changes in walking time. The relationship between multiple medication and dual-task related gait changes may have two additional explanations. First, older adults are particularly responsive to the effects of pharmacological treatment. Reduced mental alertness, slowed transmission within the central nervous system, and blurred vision are all potential mechanisms by which some medications predispose to a high risk of falling and to dual-task related gait changes (25). Second, the multiple-drug related gait effect may partly be a close measure for poor health because polymedication is a marker of comorbidity (17).

Unlike other data in the literature, our results did not demonstrate any significant effect of psychoactive drugs on dual-task related gait changes, probably because they are a surrogate measure which is less sensitive than falls. Moreover, psychoactive drug effects depend on the type of drug acting on the central nervous system (3), which was not differentiated in our study. For example, benzodiazepines probably have a higher impact on attention level and dual-task-related gait performance with respect to their sedative effect than antidepressants, such as selective serotonin-reuptake inhibitors. Dual-task related gait changes result from the interference between gait and the attention-demanding task (9). Because walking requires more attention with increasing age $(9,23)$, dual-task performance mainly depends on the cerebral capacity to split attentional resources between walking and additional attention-demanding tasks (23).

There is increasing evidence that number of chronic diseases is associated with severity of physical disability (26), possibly explaining the significant effect of abnormal mobility on dual-task related gait changes seen in our sample of transitional frail older adults. Several chronic diseases have a major effect on gait. The ability to estimate distance and to recognize obstacles and hazards is essential to safe ambulation (27). It has been shown that visual impairment is associated with a high risk of falling (4). In our study, distance visual acuity was not significantly linked to dual-task related gait changes, probably because visual acuity is not the best marker of visual decline related to safe ambulation. Previous studies have shown that contrast sensitivity and depth perception are the visual functions most closely linked to falling among older adults $(4,27)$. In addition, decrease in vision may influence fall risk through a different mechanism than the ability to combine walking with an additional attention-demanding task.

It has been reported that cognitive impairment may increase the risk of falling by directly influencing the ability to adapt gait patterns to unexpected situations of daily life (5). In our study, cognitive impairment was significantly associated with walking time changes in dualtask conditions only in bivariate analysis. After adjusting for the other intrinsic fall risk factors, there was no significant effect. This may be explained by the fact that our transitional frail older adults had relatively high levels of cognitive performance, an important requisite for performing a dual-task (9).

Our study has several limitations. The sample may not be representative of all older adults transitioning to frailty. The size of the sample was small, and the transitional frail older adults who participated in the study were probably more motivated and more interested in health issues than the general population of older adults transitioning to frailty. Moreover, excluding subjects with fall histories probably led to a subset of transitional frail older adults with fewer mobility and gait problems, which may explain the lack of association between poor health and dual-task related gait changes. Another limitation of our study was that the occurrence of falls was not studied.

In conclusion, we found that transitional frail older adults have difficulty in coping with attention-dividing walking conditions, which may represent a common fallrisk situation in this fall-prone population. Furthermore, this difficulty was closely correlated to polymedication and impaired mobility. These findings give some insight into the complexity of divided attention while walking and accentuate the need for multi-factorial, personalized intervention strategies to prevent decline in dual-task performance in this population. Further research is required to examine the relationship between dual-task related gait changes and falls, and how interventions affect such gait performance and falls.

\section{ACKNOWLEDGEMENTS}

We are grateful to our subjects for their cooperation. This work was financially supported by the Saint-Etienne University Hospitals. 


\section{REFERENCES}

1. Tinetti ME. Preventing falls in elderly persons. N Engl J Med 2003; 348: 42-9.

2. Tinetti ME, Speechley M, Ginter SE. Risk factors for falls among elderly persons living in the community. N Engl J Med 1988; 319: 1701-7.

3. Thapa PB, Gideon P, Cost TW, Milam AB, Ray WA. Antidepressants and the risk of falls among nursing home residents. $\mathrm{N}$ Engl J Med 1998; 339: 875-82.

4. Lord ST, Dayhew J. Visual risk factors for falls in older people. J Am Geriatr Soc 2001; 49: 508-15.

5. Van Doorn C, Gruber-Baldini AL, Zimmerman S, et al. Dementia as a risk factor for falls and fall injuries among nursing home residents. J Am Geriatr Soc 2003; 51: 1213-8.

6. Sihvonen S, Era P, Helenius M. Postural balance and health-related factors in middle-aged and older women with injurious falls and non-fallers. Aging Clin Exp Res 2004; 16: 139-46.

7. Janssen HC, Samson MM, Meeuwsen IB, Duursma SA, Verhaar HJ. Strength, mobility and falling in women referred to a geriatric outpatient clinic. Aging Clin Exp Res 2004; 16: 122-5.

8. Oliver D, Daly F, Martin FC, McMurdo ME. Risk factors and risk assessment tools for falls in hospital in-patients: a systematic review. Age Ageing 2004; 33: 122-30.

9. Woollacott M, Shumway-Cook A. Attention and the control of posture and gait: a review of an emerging area of research. Gait Posture 2002; 16: 1-14.

10. Beauchet O, Najafi B, Dubost V, Kamiar A, Mourey F, Kressig R. Age-related decline of gait control under a dual-task condition. J Am Geriatr Soc 2003; 51: 1187-8.

11. Beauchet O, Dubost V, Gonthier R, Kressig RW. Dual-task related gait changes in transitionally frail older adults: the type of the walking-associated cognitive task matters. Gerontology 2005; 51: 48-52.

12. Bloem BR, Steijns JAG, Smits-Engelsman BC. An update on falls. Curr Opin Neurol 2003; 16: 15-26.

13. Lundin-Olsson L, Nyberg L, Gustafson Y. "Stops walking when talking" as a predictor of falls in elderly people. Lancet 1997; 349: 617.

14. Lundin-Olsson L, Nyberg L, Gustafson Y. Attention, frailty, and falls: the effect of a manual task on basic mobility. J Am Geriatr Soc 1998; 46: 758-61.
15. Camicioli R, Howieson D, Lehman S. Kaye J. Talking while walking: the effect of a dual task in aging and Alzheimer's disease. Neurology 1997; 48: 955-8.

16. O'Shea S, Morris ME, lansek R. Dual-task interference during gait in people with Parkinson's disease: effects of motor versus cognitive secondary tasks. Phys Ther 2002; 82: 888-97.

17. Fried LP, Bandeen-Roche K, Kasper JD, Guralnik JM. Association of comorbidity with disability in older women: the Women's Health and Aging Study. J Clin Epidemiol 1999; 52: 27-37.

18. Speechley M, Tinetti M. Falls and injuries in frail and vigorous community elderly persons. J Am Geriatr Soc 1991; 39: 46-52.

19. Folstein MF, Folstein SE, McHugh PR. Mini Mental State: a pratical method for grading the cognitive state of the patient for the clinician. J Psychiatr Res 1975; 12: 189-98.

20. Sheik JI, Yesavage JA. Geriatric Depression Scale. Recent evidence and development of a shorter version. In Brink TL, ed. Clinical gerontology: a guide to assessment and intervention. New York: Howarth Press, 1986, pp. 165-73.

21. Lord SR, Ward JA, Williams P, et al. Physiological factors associated with falls in older community-dwelling women. J Am Geriatr Soc 1994; 42: 1110-7.

22. Podsiadlo D, Richardson S. "The Timed Up \& Go": a test of basic functional mobility for frail elderly persons. J Am Geriatr Soc 1991; 39: 142-9.

23. Verhaeghen $P$, Cerella J. Aging, executive control, and attention: a review of meta-analyses. Neurosci Biobehav Rev 2002; 26 : 849-57.

24. Cumming RG, Miller JP, Kelsey JL, et al. Medications and multiple falls in elderly: the St Louis OASIS study. Age Ageing 1991; 20: 455-61.

25. Campbell AJ. Drug treatment as a cause of falls in old age. A review of the offending agents. Drug Aging 1991; 1: 289-302.

26. Gunter KB, White KN, Hayes WC, Snow CM. Functional mobility discriminates nonfallers from one-time and frequent fallers. $\mathrm{J}$ Gerontol 2000; 55A: M672-6.

27. Lord ST, Dayhew J, Howland A. Multifocal glasses impaired edgecontrast sensitivity and depth perception and increase the risk of falls in older people. J Am Geriatr Soc 2002; 50: 1760-6. 